\title{
Evaluation of husband-wife communication regarding family planning among the couple of reproductive age group in the field practice area of Prathima Institute of Medical Sciences, Karimnagar
}

\author{
Dasari Gayathry $^{1}$, M. Ramsagar Reddy ${ }^{2}$, B. V. Rammana ${ }^{2}$
}

\begin{abstract}
Department of Community Medicine, ${ }^{1}$ Chalmeda Anand Rao Institute of Medical Sciences, Karimnagar, Telangana, ${ }^{2}$ Rajiv Gandhi Institute of Medical Sciences, Kadapa, Andhra Pradesh, India
\end{abstract}

Received: 22 February 2018

Revised: 27 March 2018

Accepted: 14 April 2018

\author{
*Correspondence: \\ Dr. Dasari Gayathry, \\ E-mail: gayatrispm@gmail.com
}

Copyright: ( the author(s), publisher and licensee Medip Academy. This is an open-access article distributed under the terms of the Creative Commons Attribution Non-Commercial License, which permits unrestricted non-commercial use, distribution, and reproduction in any medium, provided the original work is properly cited.

\begin{abstract}
Background: Fertility decisions occur within specific social contexts and social norms therefore restrict individual decisions on fertility and behaviors related to family planning such as spacing and limiting of births and using contraception which reflects the importance of effect of inter-spousal communication on the contraceptive method choice and future intention of method use. Hence the objective of present study is to evaluate the husband wife communication and contraceptive use, method choice and timing of initiation of discussion among couples in study area.

Methods: A cross - sectional study was conducted during February 2013 - January 2014 among couples residing in the field practice study areas. A semi-structured questionnaire consisting of socio-demographic characteristics, questions related to awareness, sources and decision making towards family planning was administered to 406 couples of study area.

Results: It has been observed that regarding decision making, about $39.4 \%$ of the men had taken a decision on the use of contraceptive methods, and only $21.7 \%$ wives had autonomy of using contraception of their choice. Around $67.5 \%$ of the men had discussion with their wives about the family planning and more than half (57\%) of the time the discussion was initiated by men.

Conclusions: Husband was the decision maker in nearly half of the couples and family planning was discussed among majority of respondents. Family planning education should be encouraged through effective IEC programs and strategies for promoting husband wife communication should be considered inorder to increase family planning adoption.
\end{abstract}

Keywords: Husband-wife communication, Family planning, Rural, Urban

\section{INTRODUCTION}

Family planning plays an important role in controlling population growth and reducing mortality, especially maternal mortality. In developing countries, there is still rapid population growth, high mortality rates and contraceptive use is still very low, as compared to developed ones. Traditionally family planning programs in developing countries have long focused on women as the subject of interest. In India, particularly, young women, virtually have no role to play or are allowed to play very limited in the making of reproductive decisions. There can be a clash of interests here between male and female members of the family, particularly given their typically asymmetric roles in child care, and the outcomes of family decisions may therefore not be 
independent of who governs those decisions. It is now increasingly recognized that the actions required to achieve improvements in reproductive health outcomes in general and maternal health in particular should also encourage men's active participation. As a result, spousal communication concerning fertility and FP has now emerged as an interesting topic in developing countries, and in particular, where fertility rate is high and contraceptive use rate is relatively low.

In the International Conference on Population and Development (ICPD) held in Cairo in 1994, the family planning was expanded to include reproductive health and emphasized that to involve men in decision making on women's reproductive health, rights and preferences, although the recognition that the husband-wife communication plays an important role in determining reproductive descions. ${ }^{1}$ Family planning communication between husband and wife is one of the factors associated with the approval of FP and couples who discuss FP matters more frequently are more likely to use a contraceptive methods. ${ }^{2}$ The various outcomes of inter spousal communications are using or not using contraception, selection of methods, when to start contraception, having or not having a child and timing of children which reflects that an understanding of the husband-wife communication on FP and its effect on pattern of contraceptive use is of utmost importance for fertility reduction. ${ }^{3}$ The frequency of inter spousal communication about family planning was the strongest determinant of in initiation of Contraceptive use. Couple practice contraception appropriately and consistently without experiencing any side effects is sometimes, can be regarded as an indicator of safe family planning practice. $^{4}$

Studies in relation to various factors contributing to prevailing low level of contraceptive use was many. A very few studied on Woman's perception of her husband's approval of FP on her current and future use of modern contraception. ${ }^{5}$ Where there is communication, the wife gets an opportunity to know her husband's attitude towards family planning and fertility desires which is believed to influence the couple's decision in initiation of modern contraceptive use. Further studies which examine the effects of husband-wife discussion on contraceptive adoption were limited. ${ }^{6}$ Fertility decisions occur within specific social contexts and social norms therefore restrict individual decisions on fertility and behaviors related to $\mathrm{FP}$, such as spacing of births, stopping child bearing and using contraception. ${ }^{7}$ These are reflecting the importance of effect of inter-spousal communication on the contraceptive method choice and future intention of contraceptive method use. Hence the objective of the present study is to evaluate the husband wife communication and contraceptive use, method choice and timing of initiation of discussion among married couples in the both field practice areas.

\section{METHODS}

A community based cross-sectional study was conducted during February 2013 - January 2014 among the couples residing in both urban and rural field practice areas of the Department of Community Medicine. The Rural Health Training Center (RHTC) is located at Vutoor and the serving area includes four villages (Vutoor, Pachnoor, Veldhi and Vegurapally) of total population 11,258. As per the village health survey, conducted by RHTC, a list of all eligible couple (1980 eligible couples) in the area was prepared and by using systematic random sampling, every 4th couple was selected for study. Urban Health Training Center (UHTC) of the department (Total population 12,200), located in a Katta Rampur area was selected for the study of urban participants. As per the previous survey a list of about 2168 eligible couples were obtained and based on the sample size by using systematic random sampling, every 5th couple was selected for the study. The sample size for this study was calculated to be 812 (203 couples each were selected from both areas, using the formula $n=z \alpha 2 p(100-p) / \varepsilon 2$ considering the estimated prevalence of use of contraceptive methods $(60 \%)$ and the margin of error on $\mathrm{p}$ (put at 5\%) with $10 \%$ non-response rate. A semistructured questionnaire was used to gather data. The study protocol was approved by the institutional ethics committee of the institute. The purpose of the study was explained and written and signed informed consent was obtained. Data was analyzed by using Epi Info Version 7 and statistical measures obtained were numbers, percentages, mean values and standard deviation. The unpaired t test was used to evaluate the difference in the mean knowledge and attitude scores in the context of gender and place of residence among the respondents.

\section{Inclusion criteria}

Inclusion criteria were couples who were in reproductive age group (15-45 years) and in a stable marital relationship (i.e. having been in a stable relationship for at least six months); those were available at the time of interview; those were willing to participate in the study and able to give informed consent.

\section{Exclusion criteria}

Exclusion criteria were couples not available at the time of data collection after frequent visits; unwilling to participate in the study; women who underwent hysterectomy.

\section{RESULTS}

In present study the mean age of the respondents was $24.89 \pm 3.62$ years. The average duration of married life of participants was $7.98 \pm 5.2$ years. The mean age of marriage of the participants was $21.71 \pm 2.3$ years. The mean parity of the couples was $1.56 \pm 1.08$ children and 
$150(37 \%)$ were having parity 2. Out of the total 406 women respondents, $326(80.3 \%)$ respondents have given birth to one or more children and $80(19.7 \%)$ of the participants have never given birth. Among 406 women $193(47.5 \%)$ of them had history of abortion in their lifetime (Table 1).

Table 1: Reproductive history of respondents.

\begin{tabular}{|llll|}
\hline Variables & & Number & Percentage (\%) \\
\hline \multirow{3}{*}{ Parity } & 0 & 80 & 19.7 \\
\cline { 2 - 4 } & 1 & 106 & 26.1 \\
\cline { 2 - 4 } & 2 & 150 & 37.0 \\
\hline \multirow{2}{*}{ Number of abortions } & 3 & 52 & 12.8 \\
\hline Total & 4 & 18 & 4.4 \\
\hline
\end{tabular}

Table 2: Awareness of respondents regarding family planning.

\begin{tabular}{|c|c|c|c|}
\hline Variables & & Number & Percentage $(\%)$ \\
\hline \multirow{2}{*}{ Aware of family planning } & Yes & 806 & 99.3 \\
\hline & No & 6 & 0.7 \\
\hline \multirow{2}{*}{ Family planning is useful to avoid unwanted births } & Yes & 519 & 63.9 \\
\hline & No & 293 & 361 \\
\hline \multirow{2}{*}{ Family planning is useful to regulate interval between births } & Yes & 251 & 30.9 \\
\hline & No & 561 & 69.1 \\
\hline \multirow{2}{*}{ Family planning is useful to determine the number of children } & Yes & 265 & 32.6 \\
\hline & No & 547 & 67.4 \\
\hline \multirow{2}{*}{ Ideal gap between two child births } & Yes & 344 & 42.4 \\
\hline & No & 468 & 57.6 \\
\hline \multirow{2}{*}{ Ideal number of children } & Yes & 486 & 59.9 \\
\hline & No & 326 & 40.1 \\
\hline \multirow{2}{*}{ Aware of OCP } & Yes & 442 & 54.4 \\
\hline & No & 370 & 45.6 \\
\hline \multirow{2}{*}{ Have you heard about Emergency contraceptives } & Yes & 186 & 22.9 \\
\hline & No & 626 & 77.1 \\
\hline \multirow{2}{*}{ Are you aware of IUDs } & Yes & 253 & 31.2 \\
\hline & No & 559 & 68.8 \\
\hline \multirow{2}{*}{ Are you aware of male condom } & Yes & 456 & 56.2 \\
\hline & No & 356 & 43.8 \\
\hline \multirow{2}{*}{ Are you aware of female condom } & Yes & 68 & 8.4 \\
\hline & No & 744 & 91.6 \\
\hline \multirow{2}{*}{$\begin{array}{l}\text { Are you aware of tubectomy is a permanent female sterilization } \\
\text { method }\end{array}$} & Yes & 568 & 70 \\
\hline & No & 244 & 30 \\
\hline \multirow{2}{*}{ Are you aware of vasectomy is a permanent male sterilization method } & Yes & 565 & 69.6 \\
\hline & No & 247 & 30.4 \\
\hline Total & & 812 & 100 \\
\hline
\end{tabular}

Yes - correct response of respondent No-Other than correct response of respondent.

Table 2 presents the awareness of respondents regarding family planning. The maximum 806 (99.3\%) of respondent were aware about family planning and only a very few $6(0.7 \%)$ were unaware. A total of $519(63.9 \%)$, considered family planning useful in avoiding unwanted pregnancies, $251(30.9 \%)$ as useful to regulate birth interval and $265(32.6 \%)$ told that family planning is useful in determining the number of children in the family. About $344(42.4 \%)$ of the participants have a correct knowledge about the ideal gap between two pregnancies. Regarding perception of the ideal number of children, about 486 (59.9\%) thought that the ideal family size comprise of two children. It was observed that the knowledge on OCPs is found to be nearly $442(54.4 \%)$, while (253) $31.2 \%$ were aware of IUDs and $456(19.6 \%)$ known about male condoms whereas only 68 (8.4\%) were aware of the female condom. Knowledge of tubectomy is nearly $568(70 \%)$ and that of the vasectomy was $565(69 \%)$. 


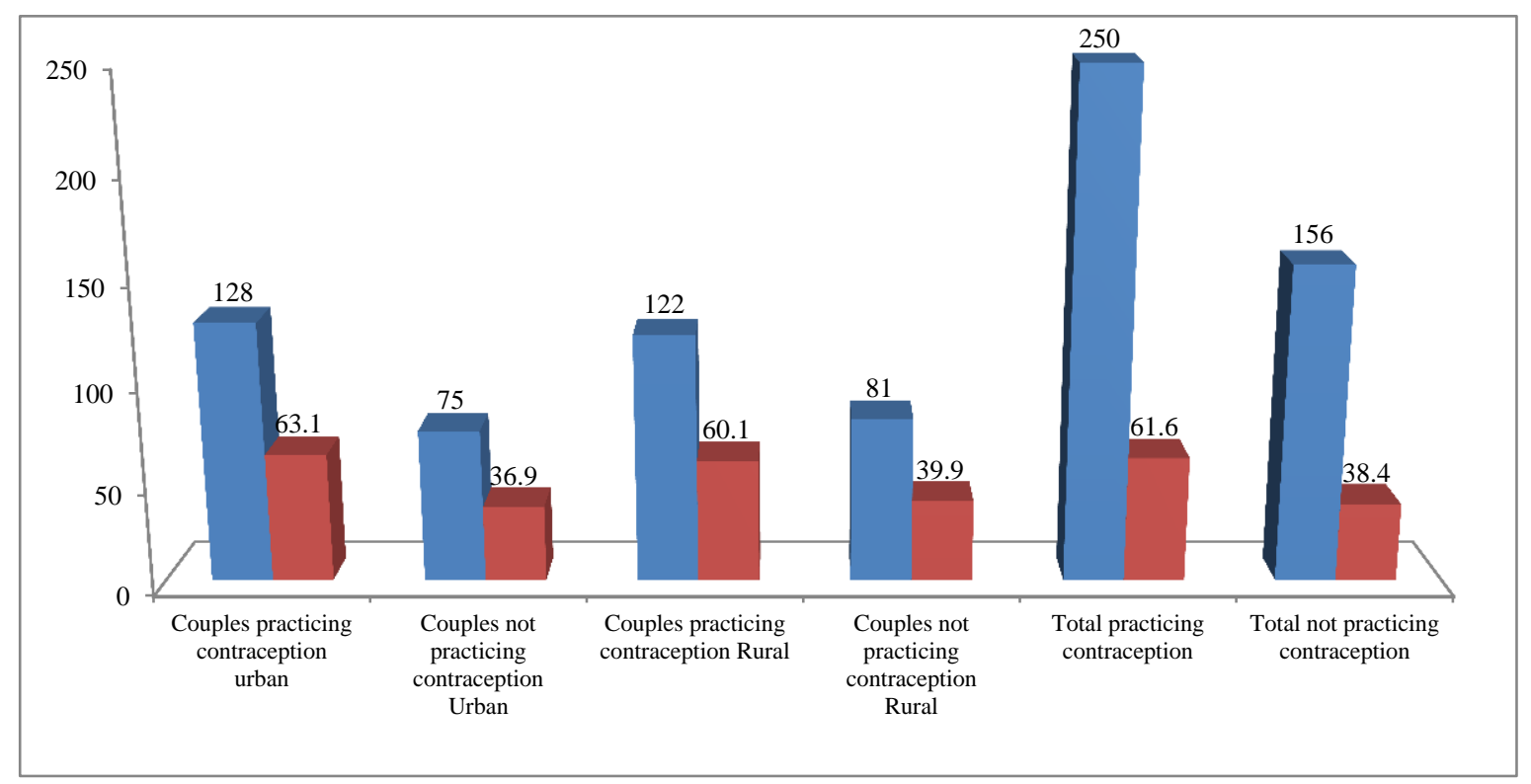

Figure 1: Bar chart distribution of practices of couples towards different methods.

Table 3: Source of family planning information and service utilization.

\begin{tabular}{|c|c|c|c|c|c|c|c|}
\hline \multirow{2}{*}{ Variables } & & \multicolumn{2}{|l|}{ Female } & \multicolumn{2}{|l|}{ Male } & \multicolumn{2}{|l|}{ Total } \\
\hline & & Number & $\%$ & Number & $\%$ & Number & $\%$ \\
\hline \multirow{7}{*}{ Sources } & Partner & 18 & 4.4 & 10 & 2.5 & 28 & 3.5 \\
\hline & Relatives & 40 & 5.0 & 25 & 3.1 & 65 & 8.0 \\
\hline & Neighbor & 10 & 1.2 & 10 & 1.2 & 8 & 2.5 \\
\hline & Parents & 6 & 1.5 & 2 & 0.5 & 8 & 1.0 \\
\hline & Media & 202 & 50 & 230 & 56.9 & 432 & 53.5 \\
\hline & Doctors & 60 & 14.9 & 100 & 24.7 & 160 & 19.8 \\
\hline & Health worker & 159 & 39.3 & 71 & 17.6 & 230 & 28.5 \\
\hline \multirow{4}{*}{ Utilization } & Government hospitals & 265 & 65.6 & 200 & 49.5 & 465 & 57.5 \\
\hline & Health centers & 137 & 33.9 & 93 & 23.0 & 230 & 28.5 \\
\hline & Private hospitals & 42 & 10.4 & 62 & 15.3 & 104 & 12.9 \\
\hline & Medical shops & 32 & 7.9 & 48 & 11.9 & 80 & 10.0 \\
\hline
\end{tabular}

*Multiple responses for source of family planning information.

Table 4: Discussion regarding family planning.

\begin{tabular}{|c|c|c|c|c|c|c|c|}
\hline \multirow{2}{*}{ Variables } & & \multicolumn{2}{|l|}{ Urban } & \multicolumn{2}{|l|}{ Rural } & \multicolumn{2}{|l|}{ Total } \\
\hline & & Number & $\%$ & Number & $\%$ & Number & $\%$ \\
\hline \multirow{3}{*}{ Discussion } & Yes & 154 & 75.9 & 120 & 59.1 & 274 & 67.5 \\
\hline & No & 59 & 24.1 & 83 & 40.9 & 132 & 32.5 \\
\hline & Total & 203 & 100 & 203 & 100 & 406 & 100 \\
\hline \multirow{4}{*}{$\begin{array}{l}\text { Discussion } \\
\text { initiation }\end{array}$} & Husband & 82 & 61.7 & 74 & 55.2 & 156 & 57.0 \\
\hline & Wife & 10 & 16.7 & 20 & 6.5 & 30 & 10.9 \\
\hline & Both & 62 & 21.7 & 26 & 41.6 & 88 & 32.1 \\
\hline & Total & 154 & 100 & 120 & 100 & 274 & 100 \\
\hline \multirow{4}{*}{$\begin{array}{l}\text { Time of } \\
\text { initiation of } \\
\text { discussion }\end{array}$} & $\begin{array}{l}\text { Immediately } \\
\text { After marriage }\end{array}$ & 58 & 23.3 & 28 & 37.7 & 86 & 31.4 \\
\hline & After $1^{\text {st }}$ child & 64 & 36.7 & 44 & 41.5 & 108 & 39.4 \\
\hline & After $2^{\text {nd }}$ child & 24 & 31.7 & 38 & 15.6 & 62 & 22.6 \\
\hline & After 3rdchild & 8 & 8.3 & 10 & 5.2 & 18 & 6.6 \\
\hline Total & & 154 & 100 & 120 & 100 & 274 & 100 \\
\hline
\end{tabular}


In Figure 1, bar chart distribution of practices of couples towards different methods. Among the 406 couples 250 (61.6\%) couples were practicing contraception, while 156 $(38.4 \%)$ were not practicing any method. It was observed that the most commonly used methods by the participants was the female sterilization 142 (568\%) followed by vasectomy $45(18 \%)$. The current usage of temporary methods was OCPs $22(8.8 \%)$, IUDs $18(7.2 \%)$ and condoms $14(5.6 \%)$ respectively. None of the respondents had used periodic abstinence in the study.

Table 3 reveals the source of information to respondents regarding family planning. In the present study majority $432(53.5 \%)$ of them obtained information through the media $230(28.5 \%)$ from the health workers and only few $28(3.5 \%)$ obtained from partner. Regarding the service uptake a total of $465(57.5 \%)$ were utilizing the services from government hospitals, $230(28.5 \%)$ from health centers and only few 104 (12.9\%) from private hospitals. Only $4(0.5 \%)$ were having not received any information on family planning.

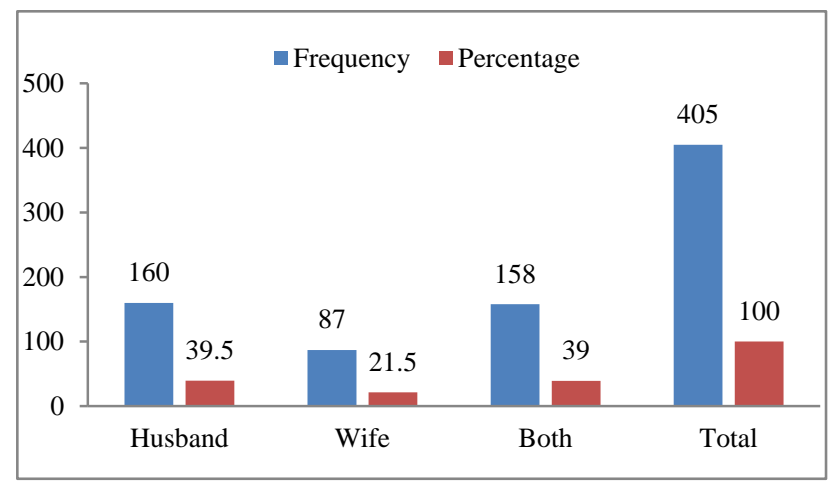

Figure 2: Decisions on the method of contraceptives to be used.

Figure 2 presents the decision on the use of contraceptive use. A total of $110(54.2 \%)$ in rural areas, while $50(24.6 \%)$ in rural men's had taken decision on the use of contraceptive methods. While majority 108 (53.2\%) of respondent had taken the joint decision in the urban areas compared to rural areas $50(24.6 \%)$.

Table 4 shows the initiation, timing and frequency of discussion. Among 406 couples, 274 (67.5\%) couples had discussions with their spouse, while 132 (32.5\%) never discussed regarding family planning. In the present study majority of male respondents had initiated discussion, while about $88(32.1 \%)$ where both spouses were involved in discussions. While considering the time of discussion, a maximum of 108 (39.4\%) started a discussion after $1^{\text {st }}$ child birth and $86(31.4 \%)$ discussed immediately after marriage. Only a few 18 (6.6\%) had discussions after 3rd child birth.

\section{DISCUSSION}

In the present study the mean age of the respondents was $32.24 \pm 6.5$ years. The average duration of married life, of participants was $7.98 \pm 5.2$ years. The mean age of marriage of the participants was $21.71 \pm 2.3$ years. The mean parity of the couples was $1.56 \pm 1.08$ children. Among the female sample, $80.4 \%$ respondents have given birth to one or more children and $47.6 \%$ of them had history of abortion in their lifetime. Sharma et al found out that $34.8 \%$ of the women in the survey were having parity 2 whereas Shafei et al found a very high mean parity (5.1) and about $12.8 \%$ of women having a history of abortion. ${ }^{8,9}$

In the context of general knowledge of family planning, the maximum, $99.3 \%$ of respondent were aware about family planning. About $59.9 \%$ thought that the ideal family size comprise of two children and majority $63.8 \%$ of considered family planning useful in avoiding unwanted pregnancies, whereas $30.7 \%$ considered it as useful to regulate birth interval and $32.4 \%$ in determining the number of children in the family. About $42.4 \%$ of the participants have a correct knowledge about the ideal gap between two pregnancies. Most respondents (94.3\%) were aware of the use of family planning in a study conducted by Obisesan et al. ${ }^{10}$

Regarding the overall knowledge of different methods in the present study, tubectomy was most popular among respondents who reported knowledge of the contraceptive methods. Knowledge of tubectomy is nearly $70 \%$ and that of the vasectomy was $69 \%$. Similar findings were observed in a study conducted among Koyas et al in Andhra Pradesh who reported nearly $75 \%$ and $67 \%$ knowledge regarding tubectomy and vasectomy respectively. ${ }^{11}$ In general, knowledge on spacing methods was low among the study population. However, knowledge on OCPs is found to be nearly $54.4 \%$, while $31.2 \%$ were aware of IUDs and $19.6 \%$ known about male condoms whereas only $8.4 \%$ were aware of the female condom. In a study by Kaushal et al distribution of knowledge about different methods were OCPs (50\%), condom (23.2\%), tubectomy (14.6\%) and IUDs (12.2\%) respectively. ${ }^{12}$ In another study conducted by the Rajesh Reddy et al it was observed that, all of the respondents $(100 \%)$ were aware of permanent methods of sterilization (both vasectomy and tubectomy). While awareness regarding temporary methods, $86 \%$ of the study population was aware of condoms, $50 \%$ OCPs, $32 \%$ abstinence and $6 \%$ IUDs. $^{13}$

We obtained multiple responses in the context of the source of information among the respondents. It has been observed that mass media played the major role in creating awareness among the study group as $53.5 \%$ of the respondents accepted it as their principal source of information. The knowledge received from the health care worker and doctors was about $28.5 \%$ and $19.8 \%$ respectively. Only $15 \%$ of the respondent obtained information from friends, relatives and peers. A study conducted by Prachi et al $54.4 \%$ had gained information from T.V / Radio, Newspapers and Magazines, 37\% from friends and relatives, and only $7.9 \%$ from health 
personnel, and findings of the study by Srivastava et al revealed that majority $70 \%$ had gained knowledge of contraceptives from friends and family followed by $39 \%$ from television and radio. ${ }^{14,15}$ Similar to findings from the 2005-2006 National Family Health Survey, the results of our study show that mass media were men's primary source of family planning information. ${ }^{16}$ In addition, our findings are in line with a national report indicating that majority of men are exposed to such messages through mass media and less than one fourth receive information through interpersonal communication with the health workers $(17.6 \%)$.

It seems that the governmental policies of contraceptive measures are more accessible in the study region as the source of acquisition as the majority of the study population has been utilizing the family planning services through Government channels, around 57.5\% from Government hospitals and $28.5 \%$ through the health centers. Nearly $12.9 \%$ of the respondents were availing the facilities from private sector, whereas few $10 \%$ were utilizing services directly from medical shops. A study conducted by Prachi et al showed that around $62.8 \%$ of the respondents were utilizing services from government hospitals and $16.4 \%$ from the private sector. ${ }^{14}$ The results of these studies showed a poor participation of private sector and there is need of expansion of public private partnership to enhance the overall performance of family planning program. Most of the couples had accessed contraceptive services from the Government health posts and lack of accessibility as a reason for not availing services was mentioned by only $1.1 \%$ of couples. To enhance the use of spacing methods, there is a need to explore the possibility of utilizing private practitioners and those from the Indian system of medicine. Hence emphasis should be made on communication and good counseling to the women giving correct information about availability, source and side effects of contraceptive methods.

Regarding decision making, the study revealed that about $39.4 \%$ of the men had taken a decision on the use of contraceptive methods, and only $21.7 \%$ wives had autonomy of using contraception of their choice. Male dominance in decision making was more predominant in rural areas compared with urban. One of the noticeable finding of the study is that around $67.5 \%$ of the men had discussion with their wives about the family planning and more than half $(57 \%)$ of the time the discussion was initiated by men. In most of the cases (39.4\%) the discussion was initiated immediately after the 1 st child birth. In a study conducted by Jayalakshmi et al in New Delhi showed that in half of the families, the husband is the sole decision-maker regarding the number of children. ${ }^{17}$

In a study conducted by Khan et al revealed that only 56 per cent of the men had discussion with their wives about the number of children they should have. More than half, $58 \%$ of the men who reported such discussion said that they discussed it immediately after marriage and in the majority of the cases of $71 \%$ it was initiated by them. ${ }^{18}$

Husbands being the decision-makers in the rural areas and to some extent even in urban area, their approval are strongly associated with contraceptive use among women. Almost all women, in our study were using a contraceptive with the knowledge and support of their husbands. However, in a very small proportion the men themselves used a contraceptive. An important indicator of the quality of family planning services is the information that women receive when they obtain contraception and the extent to which they receive follow-up services after accepting contraception. Our study reveals that around half the women had received counseling, but in only one-fifth, an informed choice was provided.

\section{CONCLUSION}

In the present study, media, health workers and doctors were the important source of information.Regarding decision making, the findings of this study revealed that about $39.4 \%$ of the men had taken a decision on the use of contraceptive methods, and only $21.7 \%$ wives had autonomy of using contraception of their choice. Male dominance in decision making was more predominant in rural areas compared with urban. One of the noticeable finding of the study is that around $67.5 \%$ of the men had discussion with their wives about the family planning and more than half $(57 \%)$ of the time the discussion was initiated by men. In most of the cases $(39.4 \%)$ the discussion was initiated immediately after the 1st child birth. Though the husband-wife communication about family planning is not necessary for adoption of certain methods; its absence may be a serious impediment to contraceptive use, which indicates that both wife and husband play important roles in accepting and adopting contraceptive use.Thus the inter spousal communication is therefore, appeared as a vital factor in eventual adoption and sustained use of contraception. Family planning education should be encouraged through effective IEC programs and strategies for promoting husband wife communication should be considered in order to increase family planning adoption, particularly targeting couples from poor communities.

Funding: No funding sources

Conflict of interest: None declared

Ethical approval: The study was approved by the Institutional Ethics Committee

\section{REFERENCES}

1. Acharya A, Sureender S. Inter-spouse communication, contraceptive use and family size: relationship examined in Bihar and Tamil Nadu. J Fam Welfare. 1996;42(4):5-11. 
2. Link CF. Spousal Communication and Contraceptive Use in Rural Nepal: An event history analysis. Stud Fam Plann. 2011;42(2):83-92.

3. Ogunjuyigbe PO, Ojofeitimi EO, Liasu A. Spousal communication, changes in partner attitude, and contraceptive use among the Yorubas of Southwest Nigeria. Ind J Comm Med. 2009;34(2):112-6.

4. Islam MA. Male involvement in reproductive health in Bangladesh: A multilevel analysis. VDM Publishing House Ltd, Germany.

5. Kamal N. The influence of husbands on contraceptive use by Bangladeshi women. Health Policy Plann. 2000;15(1):43-51.

6. Kamal SMM. Interspousal Communication on Family Planning and Its Effect on Contraceptive Adoption in Bangladesh. Asia Pac J Public Health, 2011.

7. Gebreselassie, Tesfayi, Mishra V. Spousal Agreement on Family Planning in Sub-Saharan Africa. DHS Analytical Studies No. 11. Calverton, Maryland: Macro International, 2007.

8. Sharma V, Mohan U, Das V, Awasthi S. Socio demographic determinants and knowledge, attitude, practice: Survey of family planning. J Fam Med Primary Care. 2012;1:43-7

9. Shafei MN, Shah MS, Tengku Ismail TA. Knowledge and Attitude towards Family Planning Practice and Prevalence of Short Birth Spacing Among Residents of Suburban Area in Terengganu, Malaysia. J Community Med Health Educ. 2012;2:180.

10. Obisesan KA, Adeyemo AA, Fakokunde BO. Awareness and use of family planning methods among married women in Ibadan, Nigeria. East Afr Med J. 1998;75(3):135-8.

11. Rao PD, Babu MS. Knowledge, Attitude and use of contraceptive among Racha Koyas of Andhra Pradesh. J Biological Anthropol. 2005;7(2):115-9.
12. Kaushal SK, Saxena SC, Srivastava VK, Gupta SC, Nigam S. KAP study on contraceptive methods in Kanpur District of Utter Pradesh. Indian J Community Health. 2010;21(2):33-8.

13. Rajesh Reddy S, Premarajan KC, Narayan KA, Mishra AK. Rapid appraisal of knowledge, attitude and practices related to family planning methods among men within 5 years of married life. Indian J Prev Soc Med. 2003;34;62-7.

14. Prachi R, Gupta S, Barua A, Jaju S, Khati B. A study of knowledge, attitude and practice of family planning among the women of reproductive age group in Sikkim. J Obstet Gynecol India. 2008:58;63-6.

15. Srivastava R, Srivastava DK, Jina R, et al. Contraceptive knowledge attitude and practice (KAP) survey. J Obstet Gynecol India. 2005;55:546-50.

16. National family health survey-3(NFHS-3), 2005-06, volume-1, international institute for population sciences, Deonar, Mumbai, Minstry of Health and Family Welfare, GOI.

17. Jayalakshmi MS, Ambwani K, Prabhakar PK, Swain P. A study of male involvement in family planning. Health Population Perspectives Issues. 2002;25:113-23.

18. Khan ME, Patel BC. Male involvement in family planning: A KABP study of Agra district, Indian. 2005 .

Cite this article as: Gayathry D, Reddy MR, Rammana BV. Evaluation of husband-wife communication regarding family planning among the couple of reproductive age group in the field practice area of Prathima Institute of Medical Sciences, Karimnagar. Int J Community Med Public Health 2018;5:2361-7. 